at least help to rid the ABM argument of some of the distractions of the past few months. By deciding to concentrate the defensive missiles near the strategic missile sites, local populations will be less up in arms. And although the cost of the new system is increased from $\$ 5,000$ million to $\$ 7,000$ million, less of the money will be needed in the year immediately ahead. By all accounts, indeed, the Administration is planning to begin work on only two out of ten sites, which is at once a means of giving the military people something on which to work without committing too much-in prestige as well as money-to the new weapons. At the same time, Mr Nixon seems to have done his best to keep in touch with the Russian Government in the past few days, which is at least a sign that he recognizes the delicacy of the talks on strategic missiles, not yet begun. The difficulty for the rest of us as well as $\mathrm{Mr}$ Nixon is that this compromise cannot last. In particular, if this decision is not followed quickly by some real talks on missiles with the Soviet Union, the United States will be up to its neck again in an unprecedented spate of military expenditure from which nobody will be better off.

Much will depend on what happens in Congress in the weeks ahead. The Administration will have to ask for the extra money, probably next week. It will be surprising if $\mathrm{Mr}$ Laird can get his supplement without providing a much fuller statement of his aims than has appeared so far. In passing, it will be interesting to see whether he can convince the critics of his policy that the Sentinel system is effective enough to justify the money that will be spent on it. So long as point defence depends on nuclear-armed rockets with a range of 25 miles (called Sprint), it needs only the back of a small envelope to know that multiple re-entry vehicles would be a better investment. But the real need is that the Administration should also provide a convineing account of what it plans to do about the missile talks with the Soviet Union. A year ago, there seemed a chance that something might be done. Now that the Senate has surprised everybody, itself included, by ratifying the non-proliferation treaty, the time could be ripe for another try. This is the only way out of the box which Mr Nixon has made for himself.

\section{EARTHQUAKE RESEARCH}

\section{Afiermath of Alaska}

The National Academy of Sciences, represented by the Committee on the Alaska Earthquake appointed in May 1964, has reacted to the damage which was then caused by a strong plea for more financial support for earthquake research of various kinds. Panels appointed by the committee are hard at work on a number of technical studies of various aspects of the Alaska earthquake, the first of whichon hydrology - has already been published. The committee's general argument about the need of more research appears separately in the form of a report to Dr L. Du Bridge, the President's scientific adviser (National Academy of Sciences, Washington, DC). The general theme of the report is that seismic hazards are inescapable, and that it is as necessary to work out better designs for buildings and other structures likely to be exposed to seismic shocks as to devise means for the containment of disasters caused by earthquakes.

The committee is especially concerned about the design of buildings, and seems to have been impressed by the way in which a building conforming to the building codes for seismic areas collapsed at Anchorage in Alaska while another building "designed in striking variance to the code and to accepted practice" remained standing. This is why the committee wants to see a thorough investigation of the structural problems of buildings in seismic areas. From this it follows that buildings should be regulated more effectively than at present, and there is apparently a particular need for protection against tsunamis. Dams and similar structures need frequent re-examination. One telling point in the passage which argues for a more thorough system for collecting seismic data in disturbed areas is that the gaps in the network laid down in Alaska make it impossible to learn all the lessons which the Alaskan earthquake could have provided. The tsunami hazard seems to the committee to be a particular hazard; one problem is the difficulty of predicting just when tidal waves will strike and another is that people seem not fully to appreciate the danger.

Forecasting earthquakes would, of course, be the ideal solution to the problems with which the committee has been concerned. Without promising anything, the committee says that there should be more financial support for some of the studies now being pursued which could eventually lead to means of providing "probabilistic" forecasts-measurements of ground movements and associated changes in magnetic or electrical fields and gravitational forces, for example. One step in this direction, according to the committee, would be to strengthen the World-Wide Network of Standardized Seismograph Stations established in the past few years and inspired by the attempts which have been made to detect underground nuclear explosions. Wryly, however, the committee admits that forecasting which is not entirely certain in its predictions may create as many problems as it solves, which is why the immediate objective held out to the policymakers is an attempt to make those who live in seismic areas aware of the potential hazards.

\section{ADMINISTRATION}

\section{Appointments in Washington}

THE arrival of the new Administration appears to have left undisturbed a number of senior scientific and technical people. Thus it was announced last week that Dr Thomas $O$. Paine, acting administrator of NASA since the retirement of Mr James Webb last year, has been appointed as head of the agency. This is a popular decision, for Mr Paine seems quickly to have won the respect and even affection of those who work with him, but it is also hard to see how he could decently have been replaced in the thick of a run of success with the Apollo programme in the past few months. Evidently it would have been a great mistake to engineer an upheaval within NASA before July, but a policy of no-change will also allow more freedom for the committee under Dr Charles Townes which is at work on a new strategy for space research. 